\title{
Influence of technological procedures on mechanical properties of bonded joint
}

\author{
Pavel Liška*, Barbora Nečasová and Jiři Šlanhof
}

*Correspondence:

liska.p@fce.vutbr.cz

Institute of Technology,

Mechanization

and Construction

Management, Faculty of Civil Engineering, Brno University

of Technology, Veveří 331/95,

60200 Brno, Czech Republic

\begin{abstract}
It would not be an exaggeration to say that adhesive joints have been an essential part of the construction industry for several decades now. However, a substantial disadvantage of bonded joints are the very strict requirements for adherence to the technological procedures defined by the manufacturers of assembly systems. Even a slight deviation from the recommended application steps can have a significant effect on the integrity of the entire system. In the research, five of the most common types of failure to comply with technological procedures in the realization of facade cladding were selected. The aim of the research project was to determine the extent to which a failure to adhere to technological procedures during facade construction can influence the effectiveness of the bonded joint. In construction practice, it is quite common during the implementation of a project that there are failures to comply with multiple requirements, or deviations from the prescribed procedures. For this reason, not only individual types of failure to comply with technological procedures were tested, but also their combinations. Altogether, 31 combinations of selected types of failure to comply with technological procedures were tested on one type of cladding. The adhesive joint was tested for shear strength and the adhesion of the adhesive to the substrate on a total of 352 samples. The results of the tests clearly confirm the hypothesis that failure to comply with technological procedures has a significant effect on the effectiveness of bonded joints. It is mainly the different combinations of failure to comply with technological procedures where the bonded joint loses effectiveness in the order of tens of percentage points.
\end{abstract}

Keywords: Adhesion, Adhesive, Aluminum alloy, Bonded, Ceramic tile, Cohesion, Joint, Shear, Stress, Technological procedures, Tensile

\section{Introduction}

Facades are a key element in creating modern building designs. Their area is up to $3 / 4$ of the total area of the outer surface, and this also largely influences the interior of the building. The choice of the type of sheathing structure is not only dependent on the appearance or requirements of the indoor environment but also on the maintenance, the lifetime of the structure and the assembly technology. Ventilated facades, known as "Cold Facades", are an appropriate solution. The principle of these structures is based on the airflow in the gap between the outer and inner parts of the sheathing. The exterior cladding makes the visual aspect of the building and protects the structure against climatic influences. The inner part ensures the thermal, acoustic or fire requirements [1].

(c) The Author(s) 2018. This article is distributed under the terms of the Creative Commons Attribution 4.0 International License (http://creativecommons.org/licenses/by/4.0/), which permits unrestricted use, distribution, and reproduction in any medium, provided you give appropriate credit to the original author(s) and the source, provide a link to the Creative Commons license, and indicate if changes were made. 
The first mention of these structures comes from Norway, where these structures were carried out on agricultural buildings some centuries ago [2]. In modern history, ventilated facades had not been used extensively in the US until the early 1950s. The first building with this type of sheathing was built in Pittsburgh in 1953. It was a skyscraper called Regional Enterprise Tower, the design of which was created by the Harrison and Abramovitz studio, and subsequently executed by the George A. Fuller construction company [3]. The principle of ventilated facades then spread around the world.

Anchoring of the exterior cladding of the ventilated facade to the supporting structure is usually done by screws, bolts or rivets. By the end of the twentieth century, thanks to advances in the chemical industry, adhesives began to be used. In the beginning, this was only an alternative solution. Nowadays, it is an established and completely developed anchoring system.

Bonded joints have many advantages over mechanical joints. Key advantages include: the anchoring of the cladding to the supporting structure is not visible; no local tension at the anchorages of the cladding to the supporting substructure; simple assembly; highly resistant to climatic influences and aging; no oxidation spots at the anchorages of the cladding to the supporting substructure; reduction of vibration transfer from the cladding to the supporting substructure; possibility to join various materials [4-6].

The large part of the use of bonding also play large-format cladding of irregular shapes that are indispensable for most modern buildings. Their anchoring by mechanical joints would be very complicated and difficult [7]. The ABC Museum in Madrid [8] is one of the significant buildings where the facade cladding is anchored to the supporting structure by bonding. It was a renovation, where the original structure served as a brewery and then it was adapted for the purposes of the museum in 2010. A view of a 'Bonded Facade' is shown in Fig. 1.

Although bonding has a long tradition, especially in the engineering industry [9], there is some mistrust of the experts and the general public in this type of joining system in construction. The absence of bonding in technical standards and a number of disadvantages that accompany this system also contribute to the lack of trust. Key disadvantages include: low resistance to high temperatures; poor resistance to dynamic and normal peel stress; cannot be disassembled; influence of climatic conditions during hardening (low temperatures); time needed for the adhesive to harden $[4,6]$.

Adhesion is a process during which a permanent joint of the same or different materials is created. Adhesive is a substance that allows to create such solid joint. Its properties depend on the adhesion of the adhesive to the bonded materials, as well as on the cohesion of the adhesive itself [4]. The main factors influencing the efficiency and durability of the bonded joint are: technological procedure of the application; thickness of the bonded joint; climatic influences during hardening; temperature of the bonded joint; surface treatment of bonded materials; mechanical, physical and chemical properties of adherends $[4,10]$.

Manufacturers often state in their technical data sheets that the strength of the bonded joint is guaranteed only on the assumption that the technological procedure will be followed during the installation and subsequent curing of the joint. On the other hand, they fail to mention what will happen if the technological procedure is not followed. 


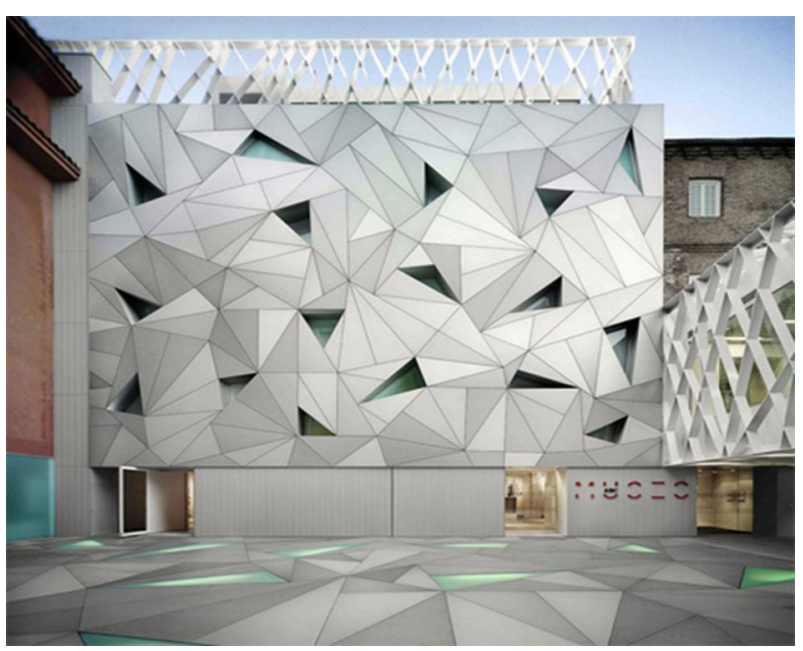

Fig. 1 'Bonded Facade' ABC Museum in Madrid [8]

It is very common in practice that the technological procedure of the manufacturer is not fully complied with, even with rigorous inspections and established management system. It may not be neglection on the part of the labourer in particular, but also time reasons when the contractor is pressed for the deadlines for the completion of the construction and subsequent sanctions for failure to meet them.

In practice, the following two situations can occur on site. In the first case, the workers will not follow one of the manufacturer's recommendations. This is the case, for example, when a bonded joint is carried out and subsequently cures at lower temperatures than what the manufacturer states. In the Czech Republic, this is a very common technological violation because the country is located in a temperate climatic zone, where temperatures in winter range from -2 to $+2{ }^{\circ} \mathrm{C}$ [11]. During this period, work is often not interrupted, which is taken into account in the expected construction dates, and therefore bonding is done also outside recommended temperatures.

In the second case, which is more common, there is a situation where more technological violations of the installation process occur at once. This include, for example, situations when the cladding is bonded to an unclean surface after the open time of the adhesive has expired.

Testing of different surface treatments of bonded surfaces is to some extent very similar to the presented research area. Surface treatment of the bonded surface has a significant effect on the effectiveness of the bonded joint, as reported by many authors [12, 13]. Violation of technological procedures as well as different surface treatments can be combined to achieve better or worse results [14].

The issue of technological indiscipline with the chosen adhesive system was already addressed in 1999 [15]. The authors of the article, Krüger and Schneider, said that technological indiscipline did not affect the strength of the bonded joint. Based on this statement, the pilot project to verify or refute this claim was started, the results of which are presented in this article. 


\section{Methods}

There are many test procedures and methods for testing bonded joint strength. The most commonly used test methods for determining mechanical properties of joints are tensile strength tests in different directions and stress angles. Since it is not possible to determine all mechanical properties by one test, joints must be tested by combining several tests $[16,17]$.

The basic mechanical test methods for testing bonded joints include: Cross-Cut Test; Peel Test; Scribe (Scratch) Test; Pull-Off (Tensile) Test; Single-Lap Shear Test; Blister Test; Micro- and Nano- Scale Tensile Testing; Four-Point Bending Test [18].

Within the project, the joints were tested for tensile and shear strength.

The essence of the first test (Tensile Test) was the measurement of the strength that would be able to tear the surface treatments of the given area from the base by vertical pull. The test is defined by the technical standard ČSN 732577 [19].

The aim of the second test (Single-Lap Shear Test) was to determine the shear stress of a single lap joint between rigid adherends on which a tensile stress is applied which is parallel to the surface of the bonded joint and the main axis of the test sample. The test is defined by the technical standard ČSN EN 1465 [20].

\section{Selection of material}

The choice of materials for testing was based on previous research on which this project is based. These were projects addressing bonded joints in terms of the bonded facades project itself.

Selected materials for the load-bearing structure, the cladding and the adhesive system are the most commonly used combinations of materials on the market. These are materials that are commonly available, their price is acceptable and their lifetime long.

Due to a large number of samples tested, only one cladding material in combination with one load-bearing structure and an adhesive system was tested.

\section{Facade cladding}

Ceramic tiles were chosen as a cladding material. It is a very durable material that needs minimal maintenance and naturally resists the effects of climatic influences. Based on the recommendations of the sheathing manufacturers, $9 \mathrm{~mm}$ thick tiles were used, which resists damage very well. The basic technical parameters are shown in Table 1.

Table 1 Selected material properties of the tested ceramic facade cladding [21]

\begin{tabular}{ll}
\hline Properties & Average values \\
\hline Bulk density & $2200 \mathrm{~kg} / \mathrm{m}^{3}$ \\
Water absorption & $0.04 \%$ \\
Flexural strength & $55 \mathrm{~N} / \mathrm{mm}^{2}$ \\
Breaking strength & $2500 \mathrm{~N}$ \\
Resistance to deep abrasion & $120 \mathrm{~mm}^{3}$ \\
Thermal expansion coefficient & $6.0 \times 10^{-6} \mathrm{~K}^{-1}$ \\
\hline
\end{tabular}




\section{Load-bearing substructure}

For bonded facades supporting structures, either structural timber or aluminium alloys are used. Aluminium was selected for the performed testing. It is a material that is very durable, solid, lightweight, and has long life. The basic technical parameters are shown in Table 2.

\section{Adhesive system}

The selection of adhesive was based on previous research, where five adhesive systems for adhesion of ventilated facades were tested in total [23]. Of these five adhesives, an adhesive system which achieved the best results was chosen. It is the SikaTack Panel adhesive system. The adhesive is one-component polyurethane which hardens in the presence of moisture in the air. Its basis is a polymer which is produced by polyaddition of diisocyanates and di- or polyhydric alcohols to form a carbon bond [24].

The chosen adhesive system is the first certified system for bonded facades that was launched approximately 20 years ago [15]. The system consists of an adhesive, a primer and a cleaning agent. The anchoring of the cladding to the supporting structure is shown in Fig. 2. The basic technical parameters of selected adhesive systems are shown in Table 3.

\section{Production of samples}

For the determination of the mechanical properties of the bonded joint, six samples (Tensile Test) or five samples (Single-Lap Shear Test) had to be made for each test and technological indiscipline. This number is based on the recommended quantity specified in standards ČSN 732577 [19] and ČSN EN 1465 [20]. In total, 352+42 (replacement for discarded samples) samples were produced.

Table 2 Selected material properties of the tested load-bearing substructuresaluminium alloy [22]

\begin{tabular}{ll}
\hline Properties & Average values \\
\hline Bulk density & $2700 \mathrm{~kg} / \mathrm{m}^{3}$ \\
Tensile strength & $65-470 \mathrm{~N} / \mathrm{mm}^{2}$ \\
Yield point & $20-400 \mathrm{~N} / \mathrm{mm}^{2}$ \\
Thermal expansion coefficient & $23 \times 10^{-6} \mathrm{~K}^{-1}$ \\
\hline
\end{tabular}

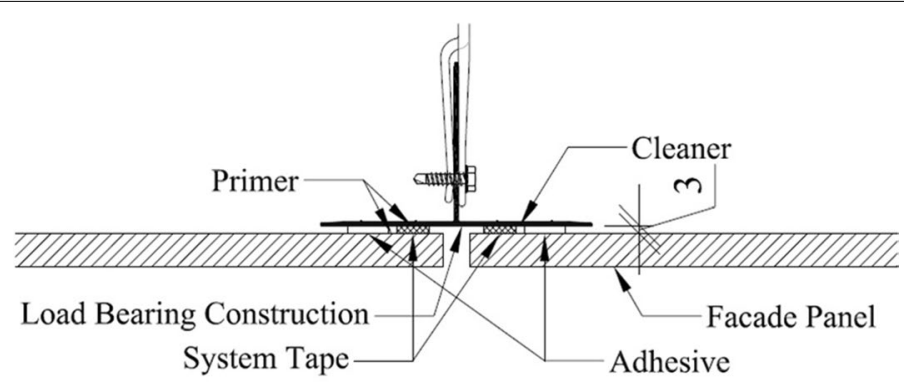

Fig. 2 Example of facade with adhesive system [15] 
Table 3 General material properties of selected adhesive system [5]

\begin{tabular}{ll}
\hline Properties & Average values \\
\hline Bulk density (DIN 53479) & $1.18 \mathrm{~kg} / \mathrm{l}$ \\
Tensile strength (DIN 53283) & $2.50 \mathrm{~N} / \mathrm{mm}^{2}$ \\
Shear strength (DIN 53504) & $2.00 \mathrm{~N} / \mathrm{mm}^{2}$ \\
Service temperature & -40 to $+90^{\circ} \mathrm{C}$ \\
Ambient temperature & +5 to $+35^{\circ} \mathrm{C}$ \\
Skinning-/laying time & $20 \mathrm{~min}$ \\
\hline
\end{tabular}

\section{Production of samples in accordance with the adhesive manufacturer's technological} procedure (standard)

In order to determine the influence of the technological indiscipline on a bonded joint, it was first necessary to produce one set of samples (standard) where all the technological procedures required by the manufacturer of the adhesive system were followed. These samples were then compared to the samples on which technological indiscipline and their combinations were applied.

\section{Production of samples in contradiction to the adhesive manufacturer's technological} procedure

Technological indiscipline consisted in non-observance of the technological procedure of the given manufacturer [5]. Within the project, the following five types of technological indiscipline were selected: no. 1 -curing of the bonded joint at $+1{ }^{\circ} \mathrm{C}$; no. 2-application of a primer on a wet cladding; no. 3-application of the adhesive on a wet primer; no. 4application of the adhesive on an dirty primer; no. 5-application of the cladding after the expiry of the open time of the adhesive. These five types of technological indiscipline were combined with each other. Their overview is given in Table 4.

In the first group (combination 1st-5th), individual technological indiscipline were not combined. One technological indiscipline was applied to each set of samples (30 for Tensile Test and 25 for shear test).

In the second group (combination 6th-15th), two technological indiscipline were combined. In total, there were 10 combinations (60 or 50 samples according to the used test method).

The third group (combination 16th-25th), included three technological indiscipline applied to one sample. In total, there were 10 combinations (the number of samples was same as in the second group).

The fourth group (combination 26th-30th), included four technological indiscipline applied to one sample. In total, there were five combinations (the number of samples was same as in the first group).

In the last group (combination 31st), all five technological indiscipline were applied to one set of samples ( 6 or 5 samples according to the given test).

\section{Technological indiscipline no. 1 -curing of the bonded joint at $+1^{\circ} \mathrm{C}$}

Test samples were inserted into a cooling chamber immediately after they were produced. The temperature inside the chamber was set to $+1{ }^{\circ} \mathrm{C}$. This temperature was chosen on the 
Table 4 The list of technological indiscipline

\begin{tabular}{|c|c|c|c|c|c|}
\hline Combination & $\begin{array}{l}\text { Technological } \\
\text { indiscipline no } 1\end{array}$ & $\begin{array}{l}\text { Technological } \\
\text { indiscipline no } 2\end{array}$ & $\begin{array}{l}\text { Technological } \\
\text { indiscipline no } 3\end{array}$ & $\begin{array}{l}\text { Technological } \\
\text { indiscipline no } 4\end{array}$ & $\begin{array}{l}\text { Technological } \\
\text { indiscipline } \\
\text { no } 5\end{array}$ \\
\hline Oth (standard) & - & - & - & - & - \\
\hline $1 s t$ & $x$ & - & - & - & - \\
\hline 2nd & - & $x$ & - & - & - \\
\hline $3 r d$ & - & - & $x$ & - & - \\
\hline 4th & - & - & - & $x$ & - \\
\hline 5th & - & - & - & - & $x$ \\
\hline 6th & $x$ & $x$ & - & - & - \\
\hline 7th & $x$ & - & $x$ & - & - \\
\hline 8th & $x$ & - & - & $x$ & - \\
\hline 9th & $x$ & - & - & - & $x$ \\
\hline 10th & - & $x$ & $\times$ & - & - \\
\hline 11th & & $x$ & - & $\times$ & - \\
\hline 12th & - & $\times$ & - & - & $x$ \\
\hline 13th & - & - & $x$ & $\times$ & - \\
\hline 14th & - & - & $x$ & - & $x$ \\
\hline 15th & - & - & - & $x$ & $x$ \\
\hline 16th & $x$ & $\times$ & $x$ & - & - \\
\hline 17th & $x$ & $x$ & - & - & $x$ \\
\hline 18th & $x$ & - & - & $\times$ & $\times$ \\
\hline 19th & - & - & $\times$ & $x$ & $\times$ \\
\hline 20th & - & $x$ & $x$ & $x$ & - \\
\hline $21 \mathrm{st}$ & $x$ & - & $x$ & $x$ & - \\
\hline $22 \mathrm{nd}$ & $x$ & $\times$ & - & $x$ & - \\
\hline $23 r d$ & - & $x$ & $x$ & - & $x$ \\
\hline 24th & $x$ & - & $x$ & - & $x$ \\
\hline 25th & - & $x$ & - & $x$ & $\times$ \\
\hline 26th & - & $\times$ & $\times$ & $x$ & $x$ \\
\hline 27th & $x$ & - & $\times$ & $x$ & $x$ \\
\hline 28th & $x$ & $x$ & - & $x$ & $x$ \\
\hline 29th & $x$ & $x$ & $x$ & - & $x$ \\
\hline 30th & $x$ & $\times$ & $\times$ & $x$ & - \\
\hline $31 \mathrm{st}$ & $x$ & $x$ & $x$ & $x$ & $x$ \\
\hline
\end{tabular}

basis of the average winter temperature in the Czech Republic (min. temperature according to the manufacturer is $+5{ }^{\circ} \mathrm{C}$ [5]). Samples were left in this chamber for 23 days. Afterwards, they were taken out and left to be cured under standard conditions for 7 days.

Technological indiscipline no. 2-application of a primer on a wet cladding

The cladding material were placed in a container with water for $24 \mathrm{~h}$. After this time, the plates were removed and the surface was wiped off. Eventually, samples were prepared. Samples cured under standard conditions. 


\section{Technological indiscipline no. 3-application of the adhesive on a wet primer}

After the primer had been applied to the plate, the adhesive was installed immediately without the required ventilation of the primer (min. drying period according to the manufacturer must be 30 min [5]). Samples cured under standard conditions.

\section{Technological indiscipline no. 4-application of the adhesive on a dirty primer}

After the primer had been applied to the plate, and the required ventilation of $30 \mathrm{~min}$, fine dust in the form of sawdust was applied to the primer. Subsequently, the adhesive was applied to the dirty primer and the cladding was bonded. Samples cured under standard conditions.

\section{Technological indiscipline no. 5-application of the cladding after the expiry of the open time} of the adhesive

The application of the cladding to the adhesive was carried out after the expiry of the open time of the adhesive, i.e. $35 \mathrm{~min}$ (max. open time of the adhesive according to the manufacturer is $20 \mathrm{~min}$ [5]). Samples cured under standard conditions.

\section{Production of samples for the Tensile Test-standard (in accordance with the adhesive manufacturer's technological procedure)}

Tensile strength samples consisted of two elements. Of the facing material (ceramic tiles) with a side length of $100 \mathrm{~mm}$ and of an aluminium alloy compensating discs with circular cross-sectional diameter of $56 \mathrm{~mm}$ and a total area of $2500 \mathrm{~mm}^{2}$ [19].

According to the technological procedure, the bonded surfaces must be treated. First, both surfaces were mechanically cleaned and the aluminium surface roughened and degreased. The cleaning agent was left to ventilate for about $10 \mathrm{~min}$. Subsequently, a primer was applied to the cleaned surfaces, which was allowed to ventilate for $30 \mathrm{~min}$. An adhesive of conical shape was applied to the cleaned surface of the ceramic tile. By pressing the aluminium disc to the adhesive, the required joint was created. The thickness of the joint $(3 \mathrm{~mm}$ ) was ensured by distance pieces.

Sample display is shown in Fig. 3a. In total, 6 samples were made.

\section{Production of samples for the Single-Lap Shear Test-standard (in accordance with the adhesive manufacturer's technological procedure)}

Samples for shear strength determination were made up of two elements measuring $25 \times 100 \mathrm{~mm}$. First, the bonded surfaces were treated in the same way as in the previous test. Then, the overlap length $(12.5 \pm 0.25 \mathrm{~mm})$ was indicated and the adhesive was applied to one plate. By pressing the second plate against it, the desired joint was created. The thickness of the joint $(3 \mathrm{~mm})$ was ensured by distance pieces $[5,20]$. In total, 5 samples were made. Sample geometry is shown in Fig. $3 \mathrm{~b}$.

Test samples were left to be cured in a dry and clean environment at an average air temperature $(23 \pm 1){ }^{\circ} \mathrm{C}$ with relative humidity $(50 \pm 5) \%$ for 30 days [25]. 


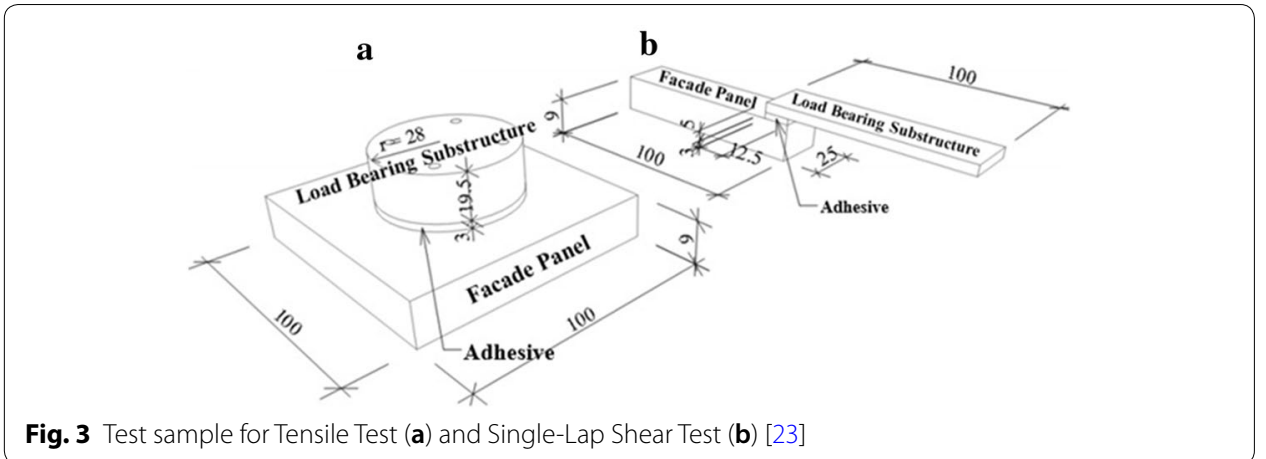

Fig. 3 Test sample for Tensile Test (a) and Single-Lap Shear Test (b) [23]

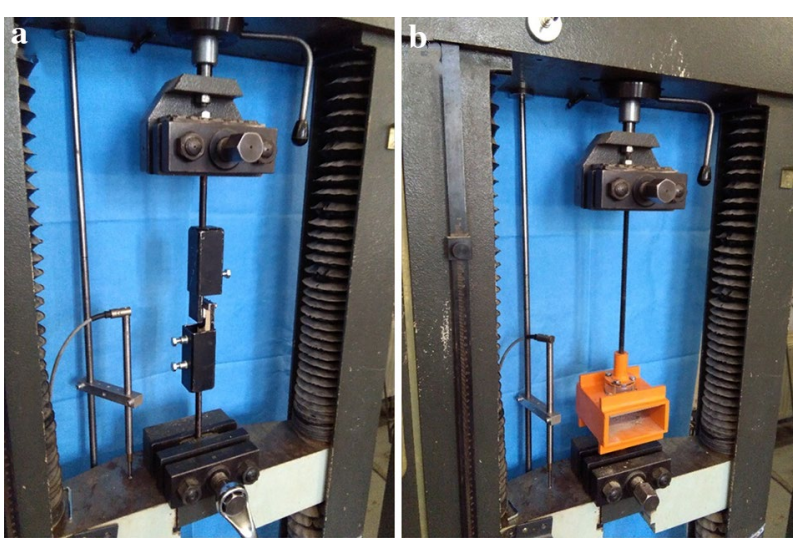

Fig. 4 Testing of shear (a) and tensile (b) strength using a tearing apparatus

\section{Testing of specimens}

To test the samples, it was necessary to produce moulds for their attachment to the tearing device. For both tests, the moulds consisted of two parts. One part was fastened to the upper fixed jaws of the device and the other to the lower moving jaws of the device. The moulds made it possible to test materials of various thicknesses while maintaining the axial stress as shown in Fig. 4. Testing was carried out on an FP 10/1 tearing device with a maximum force of $10 \mathrm{kN}$, which allowed to record the displacement achieved in relation to the stress [26].

Loading speed was $5.00 \mathrm{~mm} / \mathrm{min}$. The samples were tested to destruction.

\section{Results}

A record of the course of the stress was taken from each tested sample. This record contained a set of numbers with a force $(\mathrm{N})$ and displacement $(\mathrm{mm})$. Figures 5 and 6 show the mean values of forces and displacements calculated from six/five samples of one set transferred to the chart. The course of the 0th (standard) combination shows the mean values of samples where the technological procedure of the adhesion manufacturer was followed. The course of the 31st combination shows the mean values of forces and elongations, where all five technological indiscipline were applied. In total, there were 32 sets of samples which were then analyzed and evaluated. 


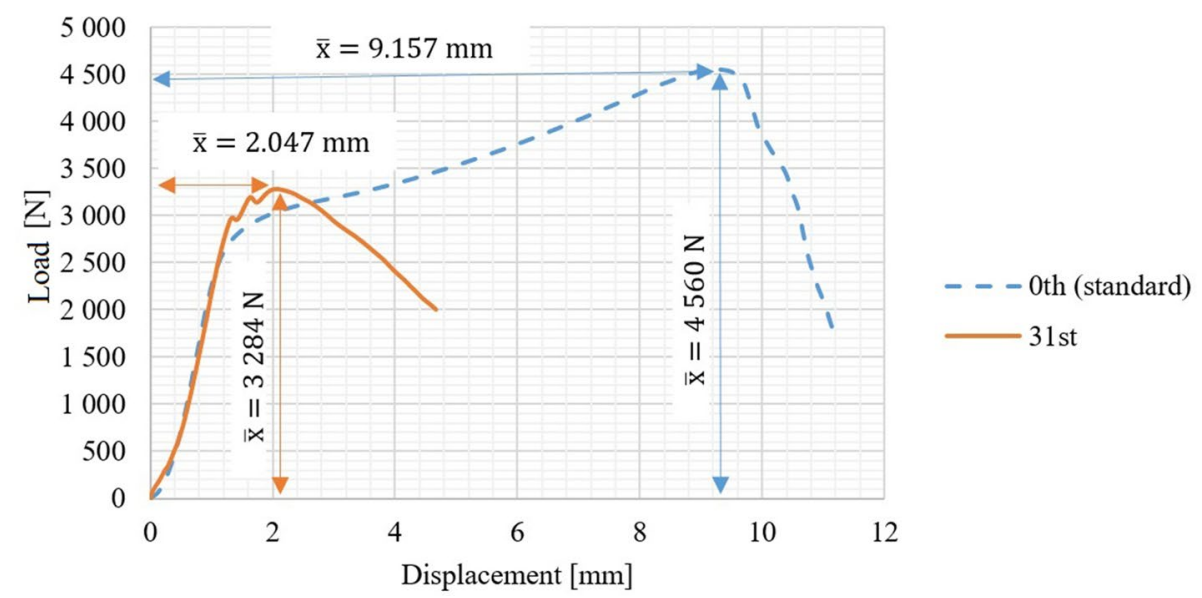

Fig. 5 Strength and displacement diagram - Tensile Test (average)

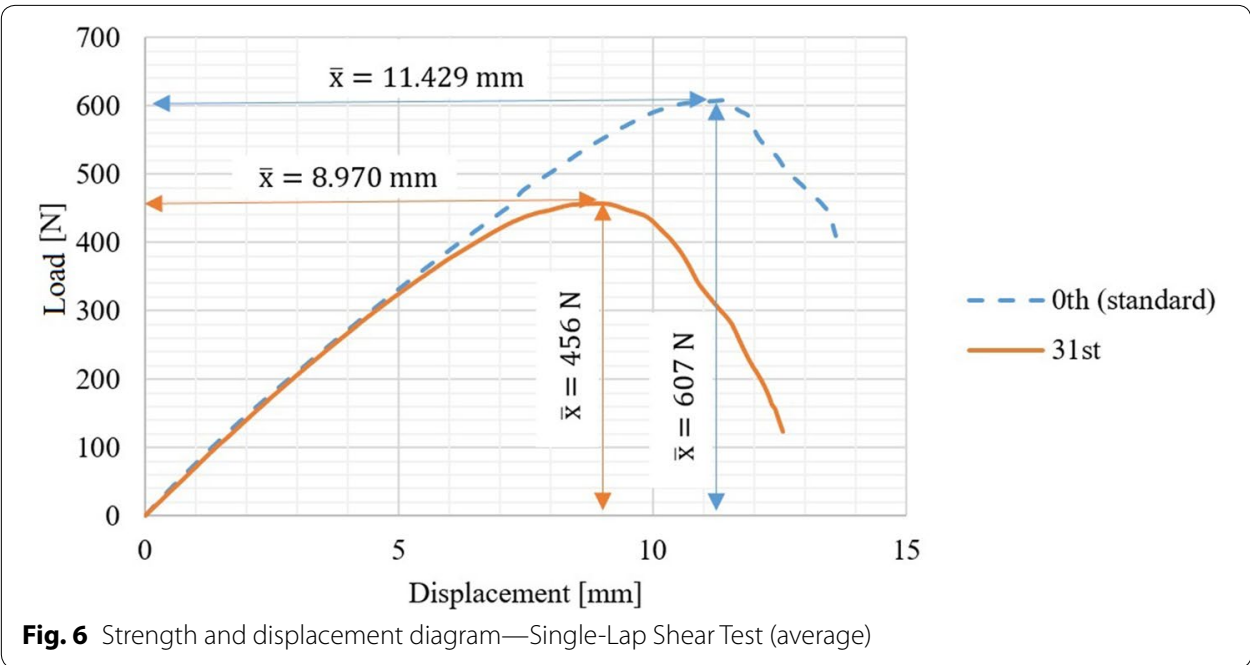

\section{Exclusion of extreme values}

In order to exclude extreme values when analyzing the results, some samples were discarded from the analysis after testing.

When testing the tensile strength, sample damage force could not be less than $70 \%$ of the average sample force of the set, otherwise the sample was excluded from the analysis [19]. In the case of shear strength testing, repeatability (the difference between two breaking forces of the adhesive sample should not be less than 2.5 times the standard deviation) and reproducibility (the difference between two breaking forces of the adhesive sample should be less than $20 \%$ of the arithmetic mean of individual test results) had to be ensured [20].

In order to maintain the recommended minimum number of samples in the set, another sample was produced, which, if the above mentioned requirements were met, was included in the analysis. 


\section{Determination of tensile stress}

Calculation of tensile and shear strength was taken from the standards ČSN 732577 [19] and ČSN EN 1465 [20].

The calculation was made according to (1).

$$
\sigma(\tau)=\frac{F}{A}
$$

where $\sigma(\tau)$ is tensile strength/shear strength, in $\mathrm{N} / \mathrm{mm}^{2}$.

$\mathrm{F}$ is the debonding force required, in N, A is the area of the disc (area of overlap) in $\mathrm{mm}^{2}$.

\section{Determination of the failure mode}

The method of damage is essential for analyzing the overall bonded joint and finding out the quality of the surface treatment of the bonded materials. A scale of five different methods of breaking bonded joint was taken from the standards ČSN ISO 10365 [27] and ASTM D5573-99 [28].

Main types of failure are: adhesive failure (AF); cohesive failure (CF); adhesive and cohesive failure (A/C $-\mathrm{F}$ ); thin layer cohesive failure (TLCF); substrate failure (SF).

Adhesion is the force of adhesive strength, i.e. the absorption force at the contact surfaces (Van de Waals forces). The range of these intermolecular forces is substantially lower than the depth of roughness of the machined surfaces. For this reason, the adhesive must penetrate such surface roughness, thereby wetting the whole surface area $[29$, 30].

Cohesion is the internal strength of the adhesive. It is a sum of all attractive forces (intermolecular forces and polymer molecule bonds), preventing the separation of individual adhesive molecules from each other $[29,30]$.

\section{Discussion}

Only samples after the removal of extreme values were included in the analysis to avoid distortion of the results. Altogether, 352 samples were analyzed. Of these, 42 samples were replaced by new ones. The method of analysis and evaluation of the samples was carried out in accordance with the valid aforementioned standards $[19,20]$. The main criteria for evaluation were the strength of the joint, its shift and the manner of damage.

\section{Tensile Test}

\section{Comparison of the strengths of bonded assemblies}

From the test results shown in Figs. 7 and 8, it is clear that the combinations of technological indiscipline significantly influenced the efficiency of the bonded joint. In the case of the first group (1st to 5th), where the technological indiscipline were applied individually, there was monitored minimal influence. The biggest decrease in strength (by $8 \%$ ) was observed in the 5th combination which includes only technological indiscipline no. 5. In this case, the cladding was attached after the adhesive time had elapsed. A thin layer with reduced adhesive properties was formed on the surface of the adhesive which prevented good adhesion. 


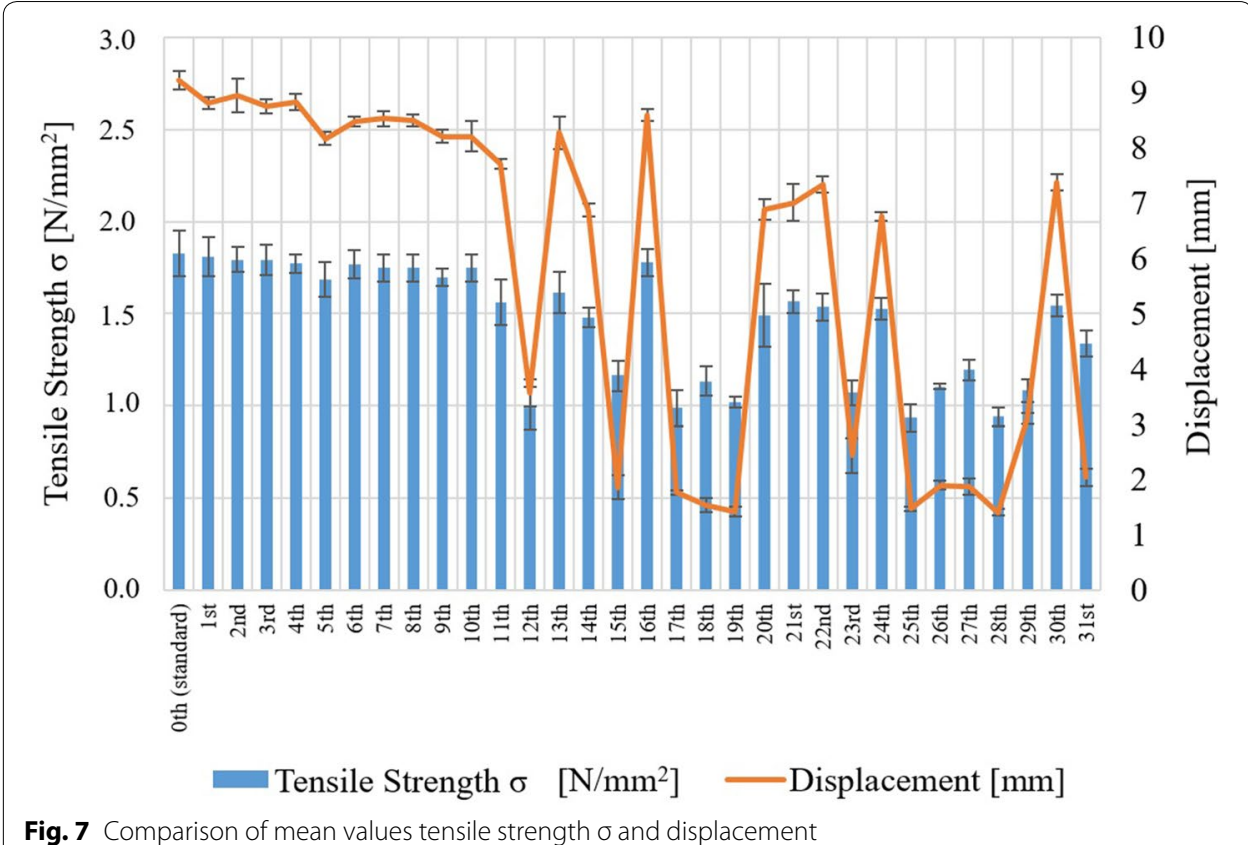

Fig. 7 Comparison of mean values tensile strength $\sigma$ and displacement

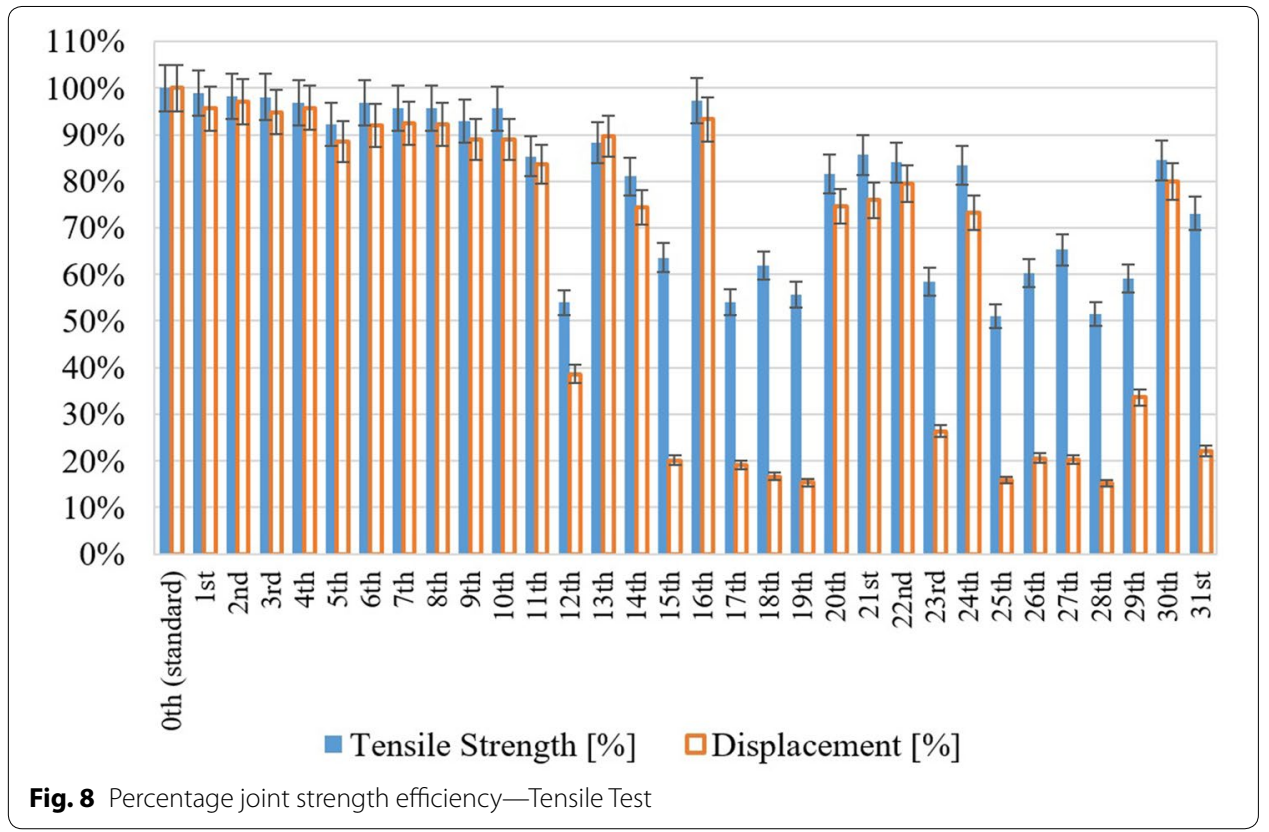

The second group (6th-15th) consisted of 10 combinations, where two technological indiscipline were applied on one sample. The biggest decrease in joint strength was monitored in the 12th combination (by $46 \%$ ). This was a combination where the primer was applied to a wet cladding. This resulted in uneven application of the primer, and the primer was also poorly adhered to the base. Subsequently, the primer was allowed to dry, i.e. ventilate, for $30 \mathrm{~min}$ and the ceramic tile was attached. The bonding was done after the adhesive time had elapsed. 
The third group (16th-25th) also consisted of 10 combinations, where three technological indiscipline were applied on one sample. The biggest decrease in joint strength was recorded in the 17th (by 46\%) and the 25th (by 49\%) combination. As for the 17th combination, the primer was applied to wet material and was then allowed to ventilate for $30 \mathrm{~min}$. The facing was attached after the adhesive time had elapsed. After cleaning, the sample was placed in the cooling chamber (the air temperature inside the chamber was set to $+1{ }^{\circ} \mathrm{C}$ ). In this case, the joint strength was reduced by $46 \%$. As for the 25 th combination, the primer was applied to a wet base and it was then allowed to dry out for $30 \mathrm{~min}$. Dirt (fine dust) was applied to such prepared surface. Finally, the facing was attached after the adhesive time had elapsed. The most considerable decrease in joint strength was in this combination (by $49 \%$ ).

The fourth group (26th-30th) consisted of 5 combinations, where four technological indiscipline were applied on one sample. The biggest decrease in joint strength was determined for the 28th combination (by $49 \%$ ). This combination included the same violations as the 25th combination. Additionally, the samples were placed in the cooling chamber as in the case of the 17th combination. It is clear from the results that technological indiscipline no. 1 (curing of the bonded joint at $+1{ }^{\circ} \mathrm{C}$ ) had no influence. The same results were obtained with both combinations.

The last group, i.e. the 31st combination, included only one set of samples, where all of the categories of technological indiscipline were applied at once. In this case, the joint strength was reduced by $27 \%$.

It could be assumed that the samples on which all the technological indiscipline were applied would show the greatest reduction in joint strength. This assumption has not been fulfilled. In the case of technological indiscipline no. 3, impurity in the form of fine dust was applied to a wet primer. Since the primer was wet, fine particles were absorbed well into it. The dirt did not create a separation layer between the primer and the adhesive.

\section{Comparison of the displacement of test specimens}

The adhesive system used is characterized by a very high tensile stress plasticity. When the elastic limit E (approx. 1.2-1.4 MPa) is reached, the force/elongation ratio is multiplied as shown in Fig. 5. For combinations where this limit was not reached, the joint was broken by adhesion, or by a combination of adhesion and cohesion. The total elongation of the joint at its damage (in most cases) was up to $40 \%$ of the standard. The smallest elongation of the joint at its damage ( $15 \%$ of the standard, i.e. $1.4 \mathrm{~mm})$ was in the case of the 19th and the 28th combination.

\section{Comparison of the failure modes of bonded assemblies}

The damage of the standard sample joint was in all cases due to the cohesion of the adhesive. This verified the compatibility of all tested elements with each other. The measured strength corresponded to about $75 \%$ of the joint strength stated in the data sheet.

In the first group of technological indiscipline, the damage of the joint was caused by adhesive cohesion in all cases. In these cases, the maximum force that the adhesive was able to withstand was achieved. This proves that the technological indiscipline had no effect on the strength of the joint. The first damage of the joint related to a technological 


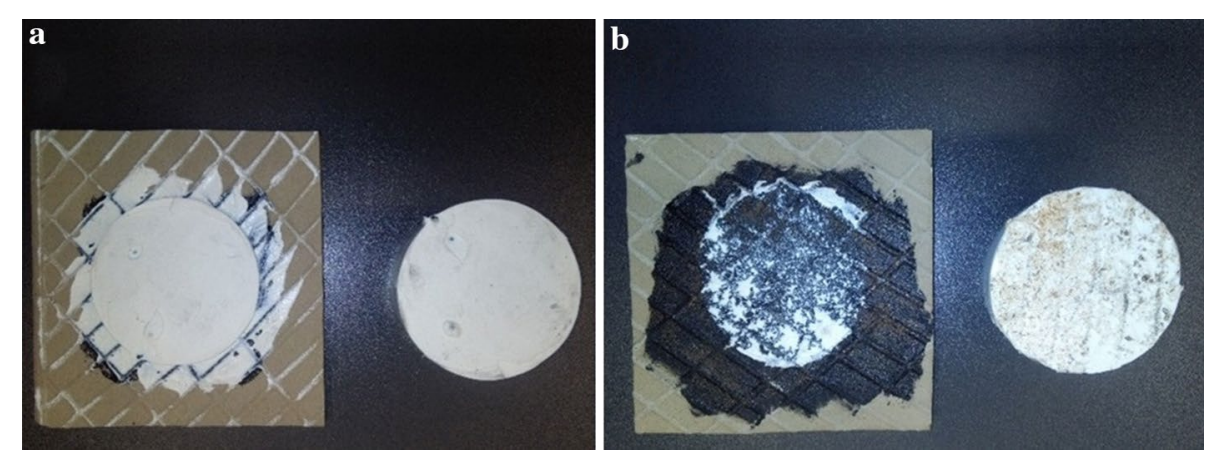

Fig. 9 Typical failure modes of bonded assemblies (Tensile Test) — Oth combination—standard—cohesive failure (a), 31 st combination-adhesive failure $(\mathbf{b})$

indiscipline did not occur before the 11th combination. It was a combination where two technological indiscipline were applied. The joints with this combination were broken in two ways. Two samples involved a failure of the adhesive cohesion, while it was a combination of adhesion and cohesion in four samples. The relationship between the mode of failure and the influence of the technological indiscipline is quite obvious.

Where the technological indiscipline had no effect whatsoever, the cohesive failure mode was observed, as shown in Fig. 9a. On the other hand, where the technological indiscipline had some influence, the failure of the joint was either due to adhesion, as shown in Fig. 9b, or a combination of adhesive and cohesive failure. In the case of technological indiscipline that affected joint strength to a lesser extent, the joint was in most cases damaged by the combination of adhesion and cohesion. For example, this included the 13th, the 20th and the 24th combination. For combinations where the technological violations had a significant influence, the joints were broken by adhesion. For example, this included the 12th, the 25 th and the 28 th combination. The predominant failure mode of tested combinations is shown in Table 5.

\section{Single-Lap Shear Test}

\section{Comparison of the strengths of bonded assemblies}

The results of the tests in Figs. 10 and 11 show that the percentage reduction in joint strength of the individual combinations partly corresponds to the previous test. As in the previous test, indiscipline which were applied separately, there was no significant reduction in strength. The biggest decrease in strength (by 8\%) was observed in the 5th combination which includes only technological indiscipline no. 5 . The similar strength decrease percentage was monitored in the previous test as well. The first more significant decrease in strength (by 18\%) was recorded in the 11th combination (the second group). A primer was applied to a wet cladding in this combination. The primer was allowed to dry for $30 \mathrm{~min}$ and then the dust was applied. Following application steps were already done according to the manufacturer's recommendations. In this group, the largest decrease was monitored in the 12th combination, as in the previous test (by $31 \%$ ).

In the third group, the greatest decrease of strength (by 35\%) was examined in the 19th combination. Dirt was applied to a wet primer and the cladding was attached immediately after the open adhesive time had elapsed. 
Table 5 Failure modes of bonded assemblies observed after Tensile Test

\begin{tabular}{|c|c|c|c|c|c|}
\hline Combination & Failure mode & Combination & Failure mode & Combination & Failure mode \\
\hline Oth & CF (100\%) & 11 th & $\begin{array}{l}C F(34 \%) \\
A / C-F(66 \%)\end{array}$ & 22nd & $\begin{array}{l}C F(34 \%) \\
A / C-F(66 \%)\end{array}$ \\
\hline $1 s t$ & CF (100\%) & 12th & AF (100\%) & $23 r d$ & AF (100\%) \\
\hline 2nd & CF (100\%) & 13th & $\begin{array}{l}C F(34 \%) \\
A / C-F(66 \%)\end{array}$ & 24th & $\begin{array}{l}A / C-F(34 \%) \\
C F(66 \%)\end{array}$ \\
\hline $3 r d$ & CF (100\%) & 14 th & AF (100\%) & 25th & AF (100\%) \\
\hline 4th & CF (100\%) & 15th & $\begin{array}{l}A / C-F(16 \%) \\
A F(84 \%)\end{array}$ & 26th & $\begin{array}{l}A / C-F(34 \%) \\
A F(66 \%)\end{array}$ \\
\hline 5th & CF (100\%) & 16th & CF (100\%) & 27 th & $\begin{array}{l}A / C-F(50 \%) \\
A F(50 \%)\end{array}$ \\
\hline 6th & CF (100\%) & 17 th & AF (100\%) & 28th & AF (100\%) \\
\hline 7th & CF (100\%) & 18th & $\begin{array}{l}A / C-F(16 \%) \\
A F(84 \%)\end{array}$ & 29th & $\mathrm{AF}(100 \%)$ \\
\hline 8th & CF (100\%) & 19th & AF (100\%) & 30th & $\begin{array}{l}C F(16 \%) \\
A / C-F(84 \%)\end{array}$ \\
\hline 9th & CF (100\%) & 20th & $A / C-F(100 \%)$ & $31 \mathrm{st}$ & $\begin{array}{l}A / C-F(34 \%) \\
A F(66 \%)\end{array}$ \\
\hline 10th & CF (100\%) & $21 s t$ & $\begin{array}{l}\text { CF (34\%) } \\
A / C-F(66 \%)\end{array}$ & & \\
\hline
\end{tabular}

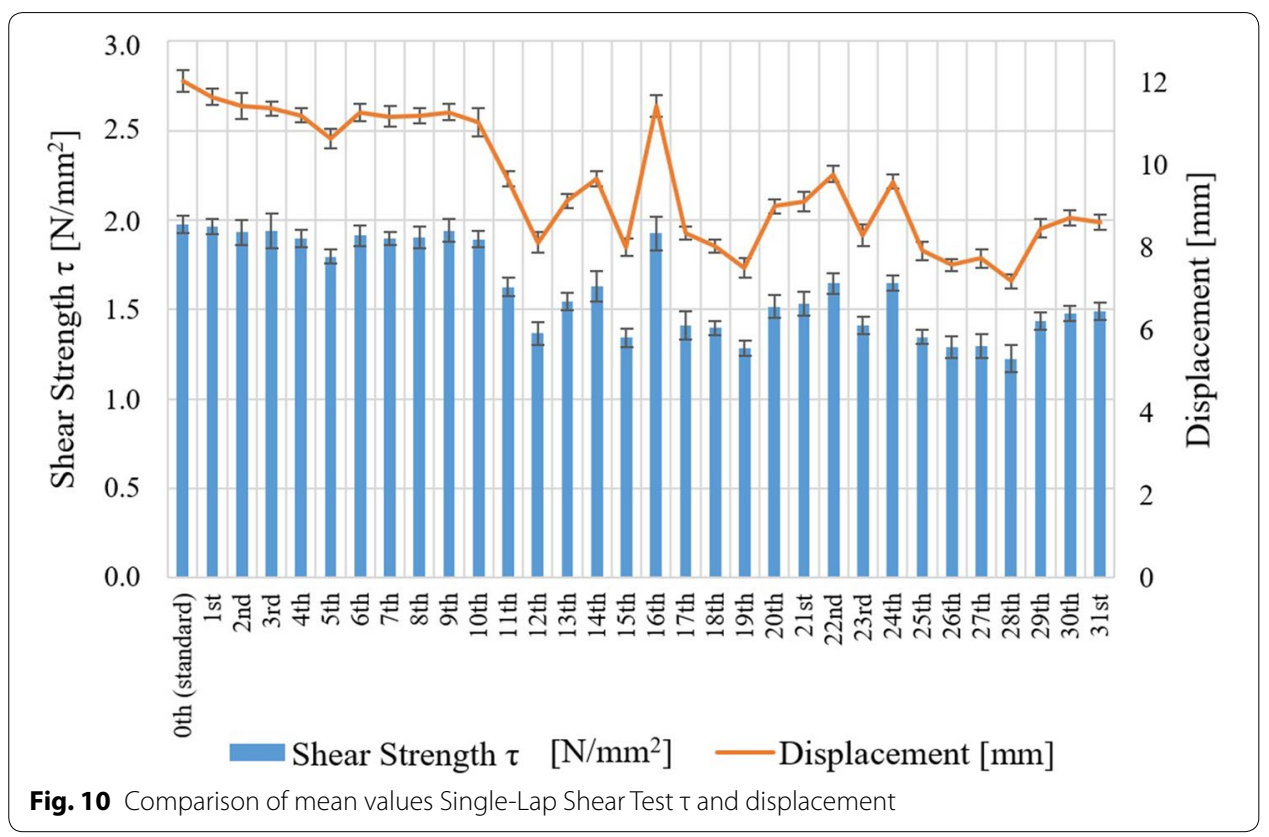

In the fourth group, the largest decrease of strength (by 38\%) was in the 28th combination, as in the previous test.

The samples on which all the categories of technological indiscipline were applied shown the joint strength reduction by $25 \%$. As with the previous test, this combination did not achieve the greatest reduction in joint strength. 


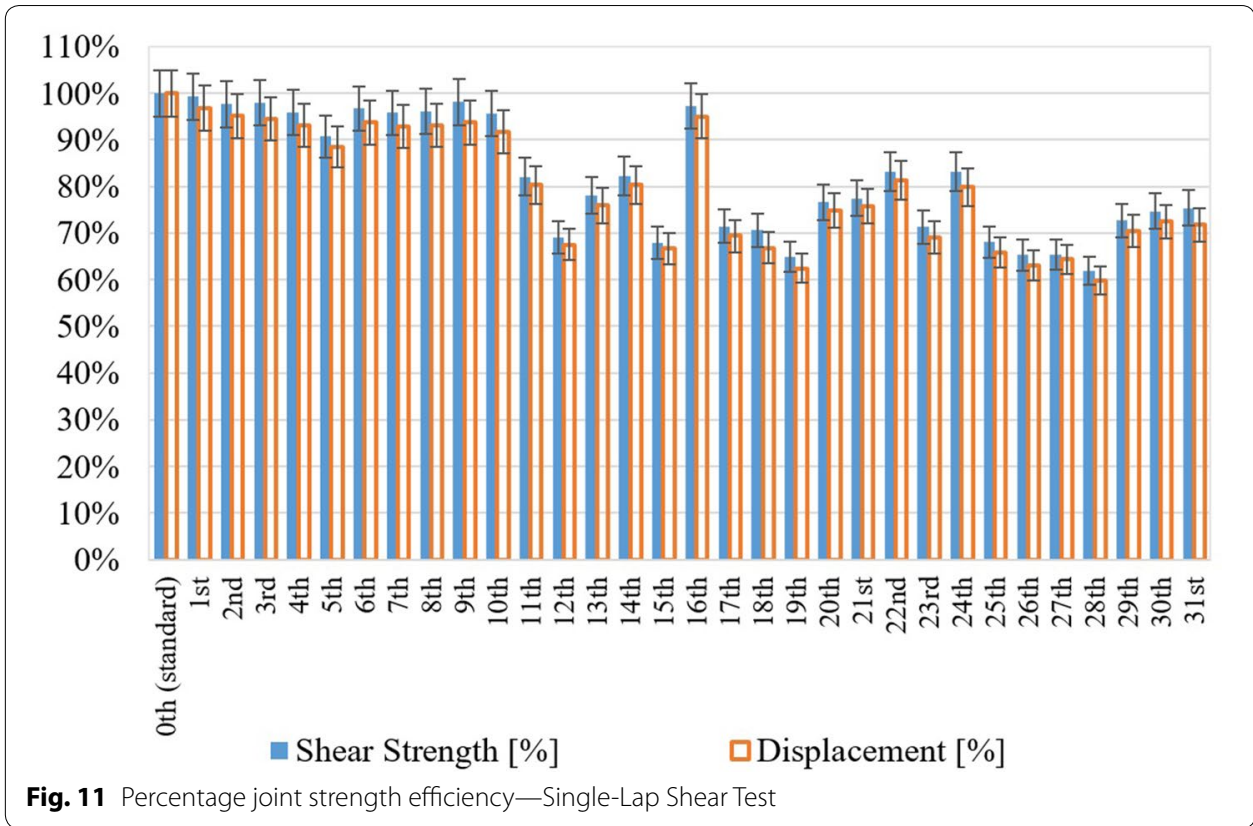

\section{Comparison of the displacement of test specimens}

In contrast to the Tensile Test, the ratio between the elongation and the reached force was constant for all combinations as shown in Figs. 10 and 11. For combinations where the force at break was higher, the elongation was higher as well and vice versa. In case of the standard, the elongation was $12.024 \mathrm{~mm}$. As for the 31st combination, where all technological indiscipline were applied, the elongation was $8.625 \mathrm{~mm}$ (by $18 \%$ less). The smallest elongation was in the case of the 28th combination. This figure was only $7.186 \mathrm{~mm}$ (less by $40 \%$ ).

\section{Comparison of the failure modes of bonded assemblies}

The damage of the standard sample joint was in all cases due to the cohesion of the adhesive. This verified the compatibility of all tested elements with each other as in the previous test, as shown in Fig. 12a. The strength corresponded to the data sheet (approx. 99\%).

As with the previous test in the first group, all samples (except one sample of the 5th combination) were damaged by the cohesive failure. This showed that the technological indiscipline which were applied separately did not affect the strength of the joint.

In the second group, the first five technological indiscipline did not affect the strength of the joint. Joints were broken by cohesive failure as well. From the 11th combination onward, samples were damaged either by adhesive failure, or a combination of adhesive and cohesive failure. In the case of these five combinations, the technological violation did have an influence.

In the third group, in almost all cases, samples were broken either by adhesion, or a combination of adhesion and cohesion (except for the 16th combination). The way the joint was broken was similar to the second group. In several cases, the sample was damaged by cohesive failure. But it was only one sample in the set. 

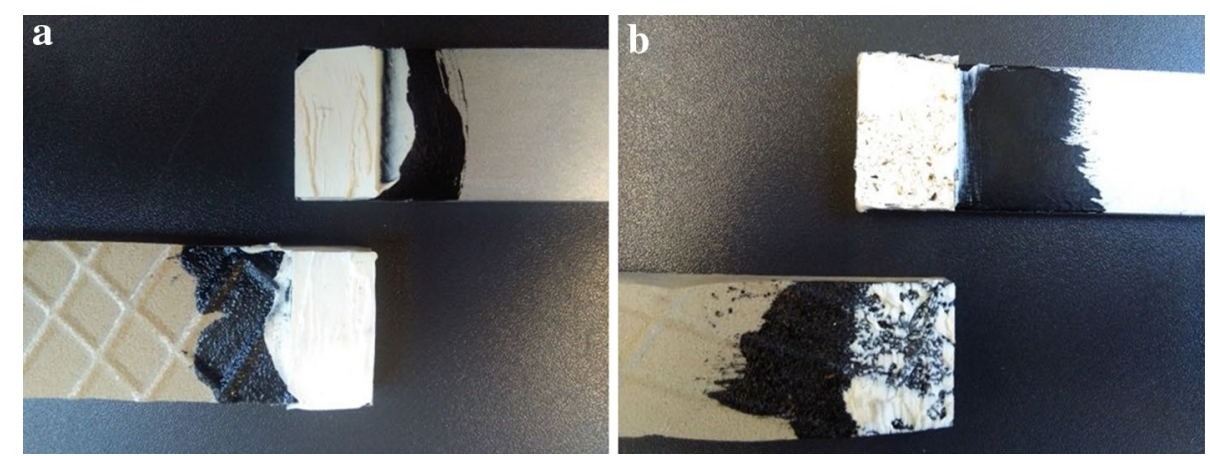

Fig. 12 Typical failure modes of bonded assemblies (Single-Lap Shear Test) — Oth combination (standard) cohesive failure (a), 31st combination-adhesive failure (b)

Table 6 Failure modes of bonded assemblies observed after Single-Lap Shear Test

\begin{tabular}{|c|c|c|c|c|c|}
\hline $\begin{array}{l}\text { Order } \\
\text { combination }\end{array}$ & Failure mode & $\begin{array}{l}\text { Order } \\
\text { combination }\end{array}$ & Failure mode & $\begin{array}{l}\text { Order } \\
\text { combination }\end{array}$ & Failure mode \\
\hline Oth & CF (100\%) & 11th & $A / C-F(100 \%)$ & 22nd & $\begin{array}{l}C F(16 \%) \\
A / C-F(84 \%)\end{array}$ \\
\hline $1 \mathrm{st}$ & CF (100\%) & 12th & $\begin{array}{l}A F(50 \%) \\
A / C-F(50 \%)\end{array}$ & $23 r d$ & $A / C-F(100 \%)$ \\
\hline 2nd & CF (100\%) & 13th & $A / C-F(100 \%)$ & 24th & $\begin{array}{l}\text { CF (16\%) } \\
A / C-F(84 \%)\end{array}$ \\
\hline $3 r d$ & CF (100\%) & 14th & $A / C-F(100 \%)$ & 25th & $\begin{array}{l}A / C-F(34 \%) \\
A F(66 \%)\end{array}$ \\
\hline 4th & CF (100\%) & 15th & $\begin{array}{l}A F(50 \%) \\
A / C-F(50 \%)\end{array}$ & 26th & $\begin{array}{l}A / C-F(34 \%) \\
A F(66 \%)\end{array}$ \\
\hline 5th & $\begin{array}{l}A / C-F(16 \%) \\
C F(84 \%)\end{array}$ & 16th & CF (100\%) & 27 th & AF (100\%) \\
\hline 6th & CF (100\%) & 17th & $\begin{array}{l}A F(34 \%) \\
A / C-F(66 \%)\end{array}$ & 28th & AF (100\%) \\
\hline 7th & CF (100\%) & 18th & $\begin{array}{l}A F(34 \%) \\
A / C-F(66 \%)\end{array}$ & 29th & $A / C-F(100 \%)$ \\
\hline 8th & CF (100\%) & 19th & $\begin{array}{l}A F(50 \%) \\
A / C-F(50 \%)\end{array}$ & 30th & $A / C-F(100 \%)$ \\
\hline 9th & CF (100\%) & 20th & $\begin{array}{l}\text { CF (16\%) } \\
A / C-F(84 \%)\end{array}$ & $31 \mathrm{st}$ & $A / C-F(100 \%)$ \\
\hline 10th & CF (100\%) & $21 \mathrm{st}$ & $A / C-F(100 \%)$ & & \\
\hline
\end{tabular}

For the 31st combination, where all of the technological violations were applied on one sample, the joint was broken in case of all samples by the combination of adhesion and cohesion, as can be seen Fig. 12b.

As with the Tensile Test, where the samples were damaged by the cohesive failure, technological indiscipline did not affect the strength of the joint. In case of samples damaged by adhesion, or a combination of adhesion and cohesion, the technological violation had an impact on joint strength.

The mode of how the joints were damaged with the individual combinations of technological indiscipline is shown in Table 6. 


\section{Conclusions}

The aim of the project was to find out to what extent the technological indiscipline has an impact on the strength of the bonded joint. The results show that the technological indiscipline has both an influence on the strength of the joint itself, but also on the manner of damage (i.e. failure mode). The initial assumption that the technological indiscipline will significantly reduce the strength of the joint is confirmed. When using the selected adhesive system and materials, there will be little reduction in joint strength if the technological indiscipline are applied separately (up to 10\%). On the other hand, when more than one technological violation is applied, the strength will be significantly reduced (by up to 50\%). The authors of the presented article already tested the influence of the technological indiscipline on the bonded joint, where same adhesive system was applied, in which they came to the comparable conclusions. However, within the previous project only porous materials were tested [31].

It is clear from the results that the combination of Technological Indiscipline no. 2, 4 and 5 had the greatest influence on the strength of the joint. This is a combination of technological violations during which the primer was applied to wet material and then allowed to dry for at least $30 \mathrm{~min}$. Dirt (fine dust) was applied to such treated surface and, when the open time of the adhesive had elapsed, the cladding was attached.

Technological Indiscipline no. 5 (application of the cladding after the expiry of the open time of the adhesive) had the largest impact. On the other hand, Technological Indiscipline no. 1 (curing of samples at low temperature of $+1{ }^{\circ} \mathrm{C}$ ) had a minimal impact even in combination with other technological indiscipline. In the next research, a lower temperature should be chosen.

The tests have shown that the tested adhesive system achieves more than $50 \%$ efficiency in combination with the selected cladding material and the supporting structure despite the non-observance of the technological procedures. Due to the fact that the technological indiscipline was applied completely in contradiction with the adhesive manufacturer's technological procedure, the reduction in adhesive strength was not so significant (e.g. up to $90 \%$ ). It can generally be stated that if the technological discipline is violated only during a single operation when carrying out a bonded joint, the impact on the efficiency of the bonded joint will be small. On the other hand, if the technological procedure is violated during multiple operations at once, the technological indiscipline do not add up, but their effects are multiplied (i.e. $1+1=3$ ).

Nevertheless, it must be pointed out that the facts found do not exclude that the technological violation with the use of another type of cladding, load-bearing structure or adhesive system will not have a greater or lesser impact than in this case.

Moreover, the application of both the primer and the fine dust was done manually. The authors of the article tried to ensure that the individual technological indiscipline were applied to all combinations identically. Unfortunately, the results show that it was not always possible. For this reason, more than $10 \%$ of the samples had to be replaced by new ones.

Based on the presented results of this project, there is an effort to develop a methodology for testing technological indiscipline to obtain more accurate results while limiting the production of new samples exhibiting extreme values. 
Further research should be directed to testing technological violations in combination with extreme stress. The stress on the bonded joint at temperatures of $-40{ }^{\circ} \mathrm{C}$ and $+80^{\circ} \mathrm{C}$ might achieve different results, as was previously verified by Banea and da Silva [32]. Since the testing of technological indiscipline was carried out under standard climatic conditions defined by [25], it was not verified what effect the indiscipline would have on the strength of the joint that would have to withstand the impact of these extremes after hardening.

\section{Abbreviations}

US: United States; ČSN: Czech Standard; EN: European Standard; DIN: German Institute for Standardization; no.: number; min.: minimum; max.: maximum; i.e.: in other words; ISO: International Organization for Standardization; ASTM: American Society for Testing and Materials; e.g.: for example.

\section{Authors' contributions}

$\mathrm{PL}$ (First and corresponding author) was responsible for completing article. BN carried out the revision and made relevant changes in the manuscript. All authors read and approved the final manuscript.

\section{Acknowledgements}

The authors would like to acknowledge the support of the Czech Ministry of Industry and Trade and Brno University of Technology.

\section{Competing interests}

The authors declare that they have no competing interests.

\section{Availability of data and materials}

All relevant data are presented in the manuscript, if needed additional information may be made available upon request.

\section{Funding}

This contribution was supported by the Czech Ministry of Industry and Trade under the TRIO Program No. FV20606 and Brno University of Technology under Grant No. FAST-S-17-4255.

\section{Publisher's Note}

Springer Nature remains neutral with regard to jurisdictional claims in published maps and institutional affiliations.

Received: 22 October 2018 Accepted: 5 December 2018

Published online: 24 December 2018

\section{References}

1. Knaack U, Klein T, Bilow M, Auer T. Facades: principles of construction. Basel: Birkhäuser; 2014.

2. Herzog T, Krippner R, Lang W (2004) Facade Construction Manual. Institute für Internationale Architektur - Dokumentation $\mathrm{GbmH}$, Munich.

3. Regional Enterprise Tower (2017) Wikipedia. org. https://en.wikipedia.org/wiki/Regional_Enterprise_Tower. Accessed 12 Apr 2018.

4. Technologie a technika lepení - základní informace (2013) Z - TRADE s. r. o. https://www.lepidla.cz/cs/a/technologi e-a-technika-lepeni-zakladniinformace.html. Accessed 1 July 2018.

5. Sika s.r.o. (2012) SikaTack-Panel system: The panel fixing system for ventilated facades. In: Product data sheet (ed.) 26/07/2012, ID 01-05-02-01-002-0.

6. Ebnesajjad S, Landrock AH. Adhesives technology handbook. London: Elsevier Inc.; 2015.

7. Lee LH. Fundamentals of adhesion. New York: Plenum Press; 1991.

8. Fachada Ventilada Museo ABC CONSTRUIBLE (2013) Grupo Tecma Red S.L. https://www.construible.es/2013/07/16/ fachada-ventilada-museo-abc. Accessed 20 June 2018.

9. Petrie MP. Handbook of adhesives \& sealants. 2nd ed. New York: The McGraw-Hill Companies Inc.; 2007.

10. Davies P. Influence of adhesive bond line thickness on joint strength. Int J Adhes Adhes. 2009;29:724-36. https://doi. org/10.1016/j.ijadhadh.2009.03.002.

11. Portál ČHMÚ (2018) Český hydrometeorologický ústav. http://portal.chmi.cz/historicka-data/pocasi/uzemni-teploty. Accessed 12 Apr 2018

12. Paiva RM, Marques EA, da Silva LF. Importance of the surface treatment in the peeling strength of joints for the shoes industry. Appl Adhes Sci. 2013. https://doi.org/10.1186/2196-4351-1-5.

13. Buček A, Brablec A, Kováčik D, Stahel P, Černák M. Glass bond adhesive strength improvement by DCSBD atmospheric-pressure plasma treatment. Int J Adhes Adhes. 2017;78:1-3. https://doi.org/10.1016/j.ijadhadh.2017.06.017.

14. Brosh T, Pilo R, Bichacho N, Blutstein R. Effect of combinations of surface treatments and bonding agents on the bond strength of repaired composites. J Prosthet Dent. 1997;77:122-6. https://doi.org/10.1016/S0022 $-3913(97), 70224-5$. 
15. Krüger G, Schneider R. An elastic adhesion system for structural bonding of facade panels. Otto-Graf-J. 1999;10:87-98.

16. Lacombe R. Adhesion measurement methods: theory and practice. New York: Taylor \& Francis Group; 2006.

17. Ebnesajjad S. Surface treatment of materials for adhesive bonding. Elsevier: William Andrew; 2014.

18. Mittal KL. Progress in Adhesion and Adhesives. New Jersey: Wiley; 2017.

19. Czech Standards Institute. $\breve{C}$ SN 732577 -test for surface finish adhesion of building structures to the base. Prague: Czech Standards Institute; 1981

20. Czech Standards Institute. ČSN EN 1465-determination of tensile lap-shear strength of bonded assemblies. Prague: Czech Standards Institute; 2009.

21. Iris Ceramica S.p.A. (2018) Technical documentation Avenue XXL. http://www.irisceramica.com. Accessed 8 July 2018.

22. Alumeco CZ s.r.o. (2018) Instrukce a návody k poznání hliníkových materiálů https://www.alumeco.cz/technickéinformace/údaje-o-hliníku/vlastnosti-hliníku?s=0. Accessed 8 July 2018.

23. Nečasová B, Liška P, Šlanhof J (2017) Research Summary: Verification of Adhesively Bonded Façade Joints. In: Proceedings of 2nd International Conference on Engineering Sciences and Technologies, ESaT 2016, Vysoke Tatry, Slovakia, 29 June-1 July 2016.

24. Polyuretan-Wikipedie (2017) Wikipedia.org. https://cs.wikipedia.org/wiki/Polyuretan. Accessed 5 Aug 2018.

25. Czech Standards Institute. ČSN EN ISO 291_Plastics_Stadnard atmospheres for conditioning and testing. Prague: Czech Standards Institute; 2009.

26. Liška P (2017) Revitalizace vybraných lehkých obvodových pláštư budov, realizovaných u nás do roku 1990. Dissertation, Brno University of Technology.

27. Czech Standards Institute. ČSN ISO 10365_adhesives. Designation of main failure patterns. Praque: Czech Standards Institute; 1995.

28. ASTM International. ASTM D 5573—Standard Practice for Classifying Failure Modes in Fiber-Reinforced-Plastic (FRP) Joints. West Conshohocken: ASTM International; 2005.

29. Osten M. Práce s lepidly a tmely. Praha: SNTL; 1982.

30. Peterka J. Lepení konstrukčních materiálů ve strojírenství. Praha: SNTL; 1980.

31. Nečasová B, Liška P, Šlanhof J. Influence of technological indiscipline on strength properties of bonded joints. Appl Mech Mater. 2015:799-800:549-53.

32. Banea MD, da Silva LFM. The effect of temperature on the mechanical properties of adhesives for the automotive industry. J Mater. 2010;224:51-62. https://doi.org/10.1243/14644207JMDA283.

\section{Submit your manuscript to a SpringerOpen ${ }^{\odot}$ journal and benefit from:}

- Convenient online submission

- Rigorous peer review

- Open access: articles freely available online

- High visibility within the field

Retaining the copyright to your article

Submit your next manuscript at $\gg$ springeropen.com 